\title{
ESTUDO DO EFEITO DO EXTRATO DE Nasturtium officinale, R. BR. NO CONTROLE DO CRESCIMENTO DE MICRORGANISMOS PRESENTES NA CAVIDADE BUCAL E PLACA DENTÁRIA IN VITRO. ${ }^{1}$
}

\section{EVALUATION OF ANTIMICROBIAL ACTIVITY OF Nasturtium officinale, R. BR. IN ORAL MICROORGANISMS}

\author{
${ }^{2}$ BUFFON, Marilene Da Cruz Magalhães; ${ }^{2}$ LIMA, Maria Lúcia Da Costa ; ${ }^{3}$ LIMA, Vismar \\ Costa Neto; ${ }^{4}$ GALARDA, Izabel; ${ }^{5}$ CARVALHO, João Luiz De Souza; ${ }^{6}$ MIGUEL, Obdulio \\ Gomes; ${ }^{6} \mathrm{MIGUEL}$, Marilis Dalarmi. \\ UNIVERSIDADE FEDERAL DO PARANÁ UFPR
}

\begin{abstract}
RECEBIDO: JANEIRO/05
ACEITE: ABRIL/2005

1 Parte da tese de doutorado em agronomiaprodução vegetalUFPR

2 Doutoranda em Produção Vegetal. Profa. do DSCUFPRe-mail: marilenebuffon@ufpr.br

3 Professor Doutor do Programa de PósGraduação em Produção VegetalUFPR.

4 Mestre em Microbiologia. Professora Sênior do Departamento de Patologia Básica UFPR.

5 Doutorando em Ciências Farmacêuticas UFPR.

6 Professor Doutor do Programa de Pós Graduação em Ciência Farmacêutica UFPR
\end{abstract}

\section{RESUMO}

Estudos têm demonstrado que a placa dental é um dos fatores determinantes para o surgimento da cárie e doença periodontal, justificando, dessa maneira, a utilização de medidas para o seu controle. Nesse sentido, colutórios contendo Nasturtium officinale $\mathrm{R}$. Br., mais conhecido como agrião, poderiam ser testados, visto que essa planta apresenta compostos com possível atividade contra microrganismos presentes na cavidade bucal. Sendo assim, o objetivo deste estudo foi avaliar in vitro a eficácia das diferentes frações obtidas do extrato bruto do Nasturtium officinale $\mathrm{R}$. Br. frente à eficácia da solução do digluconato de clorexidina a $0,2 \%$ no controle da placa dental. As amostras de placa bacteriana coletadas foram submetidas à identificação e isolamento das bactérias presentes. $\mathrm{O}$ material coletado foi inoculado em meio $\mathrm{BHI}$ com ágar e distribuído em placas de petri. Sobre a superfície do meio foram realizadas escavações e nestas foram adicionados $150 \mu \mathrm{L}$ de extratos fracionados. Após o período de incubação, foram observados e medidos os halos de inibição. Concluiu-se que as diferentes frações obtidas a partir do extrato bruto do agrião mostraram-se eficazes na inibição do crescimento de diferentes microrganismos presentes na cavidade bucal, sugerindo assim a continuidade desse estudo em avaliações pré-clínicas.

Palavras-chave: agrião; placa dental; clorexidina.

\begin{abstract}
Studies have demonstrated that dental plaque is one of the determinant factors for developing caries and periodontal disease, justifying the use of some methods for its control. In this context, extracts with Nasturtium officinale, $\mathrm{R}$. Br. (watercress) could be tested, since this plant presents compounds with possible antimicrobial activity against oral microorganisms in the biofilm. So, the aim of this study was to test in vitro the efficacy of different concentrations of this product, in comparison to the well know, chlorhexidine gluconate $0.2 \%$, in dental plaque control. The samples of collected dental plaque were identified and isolated. The material were after inoculated in $\mathrm{BHI}$ medium with agar, and divided into Petri plates. Excavations were made on the surface of the medium, and inside of them, 150 micro liters of the extract were added in different concentration gradients. After the incubation period, the zones of inhibited bacterial growth were measured and observed. It was concluded that different fractions obtained by the pure extract of watercress showed to be efficient in growing inhibition of different oral microorganisms, suggesting the continuation of this study in clinical trials.
\end{abstract}

Key-words: watercress; dental plaque; chlorhexidine. 


\section{INTRODUÇÃO}

As plantas são uma fonte importante de produtos naturais biologicamente ativos, muitos dos quais se constituem em modelos para a síntese de um grande número de fármacos. Pesquisadores da área de produtos naturais mostram-se impressionados pelo fato desses produtos encontrados na natureza revelarem uma gama quase que inacreditável de diversidade em termos de estrutura e de propriedades físico-químicas e biológicas (WALL e WANI, 1996). Apesar do aumento de estudos nessa área, os dados disponíveis revelam que apenas 15 a $17 \%$ das plantas foram estudadas quanto ao seu potencial medicinal (SOEJARTO, 1996).

Em acréscimo, o importante crescimento mundial da fitoterapia dentro de programas preventivos e curativos (GUYOT, 1990) tem estimulado a avaliação da atividade de diferentes extratos de plantas para o controle da placa bacteriana (biofilme dental). (OSAWA, 1990 a; OSAWA, 1990 b). Diversos trabalhos têm demonstrado que o biofilme dental é o fator determinante da cárie e doença periodontal, justificando desta maneira, a utilização de medidas para o seu controle. (AXELSSON e LINDHE, 1974; KORNMAN, 1986). Mesmo assim, os programas ofertados à população carente dificilmente atingem os objetivos em sua plenitude, uma vez que desvinculam os componentes sociais na incidência da cárie e doença periodontal, em função de que a maior parte da população brasileira não possui condições financeiras para aquisição periódica dos instrumentos para o controle bacteriano, quer sejam mecânicos ou químicos, fazendo com que o perfil epidemiológico brasileiro seja desastroso (BUISCHI, 1989; MEDEIROS, 1991).

Desta maneira, com a placa bacteriana não sendo adequadamente controlada, instala-se um processo de contínua destruição, comprometendo a entidade dentoperiodontal e contribuindo para diminuição da longevidade dos dentes (GLICKMAN, 1974). Este fato justifica a intensificação das medidas de prevenção da cárie e da doença periodontal baseadas no controle da placa supragengival através de meios químicos e mecânicos (SUOMI, 1971; AXELSSON e LINDHE, 1978; DE MICHELI e SARIAN, 1990).

O controle mecânico da placa tem sido o mais aceito e os agentes químicos tem sido utilizados como coadjuvantes da higiene oral quando incorporados em dentifrícios ou soluções para bochechos (CURY, 2003). As substâncias químicas mais usadas são os anti-sépticos, enzimas, compostos quaternários de amônia, alcalóides bisguanidinas, compostos fenólicos, etc.

Segundo CARVALHO (2001), o agrião (Nasturtium officinale R. Br.), é uma planta que possui uma vasta gama de utilizações na medicina e farmacologia. BLUMENTHAL et al. (2000) referem ações farmacológicas como antibacteriana, antiescorbútica, colagoga e expectorante.

As partes aéreas são consumidas em grande quantidade na alimentação humana, possuem odor característico, sabor levemente amargo e levemente picante que a torna agradável. É rica em substâncias ativas e vitaminas sendo utilizada no tratamento de infecções do trato urinário em crianças é também considerada expectorante para tratamento de bronquites, de acordo com BLUMENTHAL et al. (2000). Há indicações de uso no tratamento de icterícia e em doenças periodontais como as gengivites, segundo LOGGIA(1993).

CARVALHO (2001) afirma que inúmeras pesquisas farmacológicas demonstraram a utilização do agrião como fator protetor dos pulmões de fumantes 
contra agentes carcinógenos presentes no tabaco. Dietas que incluem o agrião podem ajudar a inibir a formação do 4-(metilnitrosamino)-1-(3-piridyl-1-butanona), ou NNK. O NNK é um carcinógeno presente no tabaco, que contribui para etiologia do câncer do pulmão. O isotiocianato feniletil isotiocianato (PEITC), liberado na mastigação da folha do agrião pela hidrólise enzimática de glucosinolatos é um agente químico preventivo contra o câncer do pulmão. Estudos pré-clínicos demonstraram que o PEITC inibiu a tumorigênesis de pulmão induzida pela nitrosamina, a qual é um potente carcinogênico específico do tabaco. Para determinar biodisponibilidade do PEITC a partir do seu precursor glucosinolato, análises em material biológico animal foram conduzidas, as quais tem demonstrado que o PEITC é liberado após ingestão da folha de agrião, segundo BLUMENTHAL et al. (2000).

GETAHUN e CHUNG (1999) demonstraram que glucosinolatos são convertidos em isotiocianatos em humanos depois da ingestão de agrião cozido, onde as mirrosinases foram completamente inativadas. A extensão da conversão, entretanto, é consideravelmente menor que a da ingestão de agrião cru. Além disso, foi sugerido que a microflora intestinal é uma boa fonte para a hidrólise de glucosinolatos a isotiocianatos em humanos.

Nesse contexto, há constante necessidade de se avaliar meios alternativos e economicamente viáveis para o controle de placa bacteriana (biofilme dental) que permitam o benefício de um contingente maior de pessoas. Por essa razão, a fitoterapia seria mais um recurso dentro de programas preventivos e curativos importantes para a saúde bucal da população (BUFFON, 2001).

Desta forma a realização do estudo in vitro do efeito do extrato de agrião, Nasturtium officinale $\mathrm{R}$. Br., no controle do biofilme dental representa um importante fator na contribuição de informações para o desenvolvimento de fitoterápicos, reforçando a possível utilização dos extrativos brutos vegetais como um método de controle de doenças bucais.

\section{MATERIAL E MÉTODO}

\subsection{MATERIAL}

Foram testados as seguintes frações do extrato de agrião (Nasturtium officinale R. Br.): solução 1 - extrato bruto, solução 2- fração hexânica; solução 3 - fração diclorometano; solução 4- fração acetato de etila; solução 5 - fração metanólica; solução 6 - fração etanólica. Estas frações foram testadas sobre cultivo misto de bactérias relacionadas a microbiota bucal que podem estar presentes na placa dentária. Foram realizados testes com culturas puras - ATCC - (American Type Culture Collection): Staphylococcus epidermidis (ATCC 12.228), Staphylococcus aureus (ATCC 25.923), Streptococcus pyogenes (ATCC 35.037), Pseudomonas aeruginosa (ATCC 25.853), Streptococcus mutans (ATCC 25.175), Streptococcus mitis (ATCC 49.456), Candida albicans (ATCC 51.501) e placa-dentária.

De acordo com BURNETT et al (1985) o Streptococcus pyogenes, isolado ocasionalmente na cavidade bucal, deriva provavelmente da oronasofaringe e não deve ser considerado um componente da flora residente. Os Staphylococcus epidermidis e Staphylococcus aureus; estão geralmente presentes na cavidade bucal e orofaringe, porém constituindo uma fração menor da flora microbiana da região e são 
Freqüentemente encontrados, constituindo uma fração significativa da flora microbiana na região da nasofaringe. O Pseudomonas aeruginosa é freqüentemente encontrado na cavidade bucal, porém em números baixos, como componentes transitórios.

Os Streptococcus mitis está relacionado com os microrganismos que iniciam a formação do biofilme, o Streptococcus mutans está relacionado com o desenvolvimento inicial de lesões de cárie e a Candida albicans é considerado um fungo com potencial muito patogênico na cavidade bucal.

\subsection{MÉTODO}

Foi utilizado o meio de cultura BHI (Brain Heart Infusion) com ágar, com cerca de $6 \mathrm{~mm}$ de espessura distribuído em placas de petri de $10 \mathrm{~cm}$ de diâmetro, sobre a superfície do meio foram feitas escavações de cerca de $7 \mathrm{~mm}$ de diâmetro. Nestas escavações foram colocados os extratos na quantidade de 150 microlitros, por meio de uma pipeta automática. A figura 1 ilustra a disposição das escavações, com as soluções 1, 2, 3, 4, 5 e 6 em torno da solução 7 . Para a solução 1 - $150 \mu \mathrm{L}$ equivalem a $42 \mathrm{mg} / \mathrm{mL}$; na solução 2 - $150 \mu \mathrm{L}$ equivalem a $1,5 \mathrm{mg} / \mathrm{mL}$; na solução $3-150 \mu \mathrm{L}$ equivalem a $1,35 \mathrm{mg} / \mathrm{mL}$; na solução $4-150 \mu \mathrm{L}$ equivalem a $0,9 \mathrm{mg} / \mathrm{mL}$; na solução $5-150 \mu \mathrm{L}$ equivalem a $7,5 \mathrm{mg} / \mathrm{mL}$; na solução 6 - $150 \mu \mathrm{L}$ equivalem a concentração de $9 \mathrm{mg} / \mathrm{mL}$; para solução $7-150 \mu \mathrm{L}$ equivalem a $3 \mathrm{mg} / \mathrm{mL}$.

A suspensão de bactérias foi preparada, comparando-se a turbidez com o tubo $\mathrm{n}^{\circ} 5$ da Escala de MacFarland.

Um Swab de algodão não tóxico, esterilizado foi submerso no inóculo. Para eliminar o excesso de líquido o Swab foi pressionado e girado contra as paredes do tubo. Em seguida foi realizada a semeadura no meio de cultivo, com cuidado de distribuir o inóculo de maneira uniforme.

As placas foram incubadas em estufa bacteriológica por um período de 24 a 48 horas, a $37^{\circ} \mathrm{C}$.

Para o teste de sensibilidade dos Streptococcus mutans as placas do BHI ágar foram incubadas em jarras para microaerofilia.

Após a incubação de 24 a 48 horas a $37^{\circ} \mathrm{C}$, observou-se o crescimento bacteriano ao redor das escavações ou a sua ausência, em forma de halos. Os diâmetros dos halos de inibição foram medidos com auxílio de régua e lupa.

Em todos os experimentos, como termo de comparação e como teste positivo, foi utilizada a solução de digluconato de clorexidina a $0,2 \%$. Foram realizadas 8 repetições para cada grupo de bactérias.

Avaliou-se o efeito de sete extratos na inibição de sete microrganismos e placa dentária. O experimento foi conduzido fazendo-se a cultura de cada microrganismo em uma placa de petri diferente. Em cada placa foi aplicado as sete soluções, cada uma em um ponto diferente da placa. Foram realizadas oito repetições, com um total de 64 placas. O experimento utilizou um delineamento inteiramente casualizado, analisados pelo ANOVA e Teste de Tukey. A figura 2 ilustra uma placa de petri semeada com placa dentária, evidenciando halos de inibição, solução 3 (à esquerda) e da solução 7 (à direita). A figura 3 ilustra inibição de crescimento dos Streptococcus mutans, resultados obtidos com o extrato bruto (solução 1). 

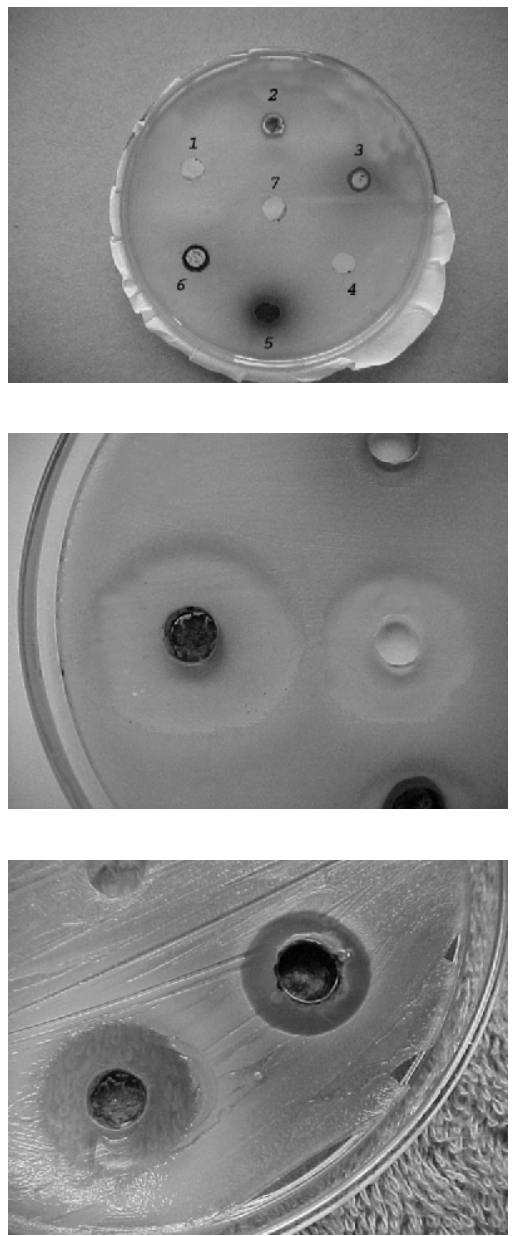

FIGURA 1 DISPOSIÇÃO DAS SOLUÇÕES DE EXTRATOS DE AGRIÃO: SOLUÇÃO 1 EXTRATO BRUTO, SOLUÇÃO 2 FRAÇÃO HEXÂNICA, SOLUÇÃO 3 FRAÇÃO DICLOROMETANO, SOLUÇÃO 4 FRAÇÃO ACETATO DE ETILA, SOLUÇÃO 5 FRAÇÃ̃O METANÓLICA e SOLUÇÃO 6 FRAÇÃO ETANÓLICA; EM TORNO DA SOLUÇÃO 7 DIGLUCONATO DE CLOREXIDINAA $0,2 \%$

FIGURA 2 PLACA DE PETRI SEMEADA COM PLACA DENTÁRIA ILUSTRANDO INIBIÇÃO DE CRESCIMENTO DE MICRORGANISMOS PRESENTES NA PLACA DENTÁRIA, QUANDO TESTADOS O EXTRATO DE AGRIÃO (Nasturtium officinale R. Br.) FRAÇÃO DICLOROMETANO (À ESQUERDA) E A SOLUÇÃO DE CLOREXIDINAA 0,2\% (À DIREITA)

FIGURA 3 PLACA DE PETRI SEMEADA COM Streptococcus mutans, DEMONSTRA INIBIÇÃO DE CRESCIMENTO (EM FORMA DE HALOS), QUANDO TESTADOS AS SOLUÇÕES: DE EXTRATO DE AGRIÃO, SOLUÇÃO 2 FRAÇÃO HEXÂNICA (À DIREITA) E SOLUÇÃO 6 - FRAÇẪO ETANÓLICA(À ESQUERDA)

\section{RESULTADO E DISCUSSÃO}

Os dados obtidos foram analisados considerando o halo de inibição em função dos microrganismos e dos extratos. O delineamento do experimento foi em parcelas subdivididas, sendo cada placa de cultura de microrganismos uma parcela. Cada parcela do experimento foi formada pela combinação dos microrganismos e dos extratos. Os resultados de halos de inibição de diferentes frações obtidas a partir do extrato de Nasturtium officinale, $R$. BR e do gluconato de clorhexidine a $0,2 \%$ frente a microrganismos da cavidade bucal e placa dental estão expressos na Tabela 1.

TABELA 1 - COMPARAÇÃO DE HALOS DE INIBIÇÃO EM mm (MÉDIA) DE DIFERENTES FRAÇÕES (SOLUÇÕES) OBTIDAS A PARTIR DO EXTRATO DE AGRIÃO D'ÁGUA (Nasturtium officinale R. BR.) E DO DIGLUCONATO DE CLOREXIDINAA 0,2\% FRENTE A MICRORGANISMOS DA CAVIDADE BUCALE PLACADENTAL 
Avaliando-se os resultados da relação Staphylococcus epidermidis em relação as diferentes soluções, verificou-se que as soluções 1, 2, 3, 4, 5 e 6 não apresentaram diferenças significativas entre si. Sendo que a solução 7 apresentou diferença significativa em relação às soluções 1, 2, 3, 4, 5 e 6 .

Verificando-se os resultados da relação Staphylococcus aureus em relação as diferentes soluções, observou-se que as soluções 1, 2, 3, 4, 5 e 6 não apresentaram diferenças significativas entre si. Sendo que a solução 7 apresentou diferença significativa em relação às soluções $1,2,3,4,5$ e 6 .

Com base nos resultados da relação Pseudomonas aeruginosa em relação as diferentes soluções, avaliou-se que a solução 1 apresentou diferença significativa em relação às soluções 2, 4 e 6; a solução 2 apresentou diferença significativa em relação à solução 4; a solução 3 apresentou diferença significativa em relação às soluções 4 e 6; a solução 5 apresentou diferença significativa em relação à solução 6; a solução 7 apresentou diferença significativa em relação às soluções 1, 2, 3, 4, 5 e 6.

Analisando-se os resultados da relação Streptococcus mutans em relação as diferentes soluções, verificou-se que as soluções 1, 2 e 6 apresentaram diferenças significativas em relação às soluções 3,4 e 5; e a solução 7 apresentou diferença significativa em relação às soluções 1, 2, 3, 4, 5 e 6.

Os resultados da relação placa bacteriana em relação as diferentes soluções mostraram que a solução 1 apresentou diferença significativa em relação à solução 3; as soluções 2, 4, 5 e 6 não apresentaram diferenças significativas das demais; a solução 3 apresentou diferença significativa em relação às soluções 1 , 2, 4 e 5; a solução 7 apresentou diferença significativa em relação às soluções 1, 2, 4 e 5.

E os resultados da relação Candida albicans em relação as diferentes soluções evidenciaram que as soluções 1, 3, 4, 5 e 6 não apresentaram diferenças significativas das demais; a solução 2 apresentou diferença significativa em relação às soluções 4 e 5 ; e a solução 7 apresentou diferença significativa em relação às soluções 1 , 2, 3, 4, 5 e 6.

Ainda analisando a Tabela 1 com base no Teste de Tukey, avaliamos que a solução 1 apresentou um resultado mais expressivo na inibição de crescimento dos Streptococcus mutans e Streptococcus mitis. A solução 3 apresentou melhores resultados o controle do crescimento das bactérias presentes na placa bacteriana. A solução 4 mostrou-se efetiva na inibição de crescimento dos Streptococcus mitis. A solução 5 apresentou resultados mais expressivos na inibição do crescimento dos Streptococcus mitis, Streptococcus mutans e placa bacteriana. A solução 6 ou seja a fração etanólica, apresentou resultados mais expressivos para Streptococcus pyogenses, Streptococcus mitis, Streptococcus mutans e placa bacteriana. A solução 7 (controle positivo) foi mais expressiva para Streptococcus mutans, seguidos de Streptococcus mitis, Candida albicans e Staphylococcus aureus.

As frações (soluções) obtidas do agrião (Nasturtium officinale R. BR.), mostraram-se eficazes no controle do crescimento de microrganismos presentes na cavidade bucal e placa dental, com resultados de algumas frações muito próximos aos resultados obtidos pelo controle positivo (solução 7). DIXON et al. (1983) e SATO et al. (1996), atribuíram aos flavanóides (são sintetizados pelas plantas para defesa contra infecções por microrganismos), uma potente atividade contra os Streptococcus envolvidos na formação de placas dentárias; e como também para os Staphylococcus aureus. O Nasturtium officinale R. Br. é rico em flavonóides, justificando assim os resultados obtidos. O efeito antiplaca da clorexidina é conhecido há mais de 20 anos e, 


\begin{tabular}{|c|c|c|c|c|c|c|c|c|}
\hline $\begin{array}{l}\text { Soluçăo/ } \\
\text { Concentraçắo }\end{array}$ & Su & S. mi. & S.e. & S. a & P. a & S. $m$ & Pd & C. a \\
\hline $\begin{array}{l}1 \text { - Extrato Bruto } \\
42 \mathrm{mg} / \mathrm{mL}\end{array}$ & 10,3 & 17,1 & 11,0 & 11,3 & 11,1 & 16,5 & 12,9 & 9,1 \\
\hline $\begin{array}{l}2 \text { - Fração Hexânica } \\
\qquad 1,5 \mathrm{mg} / \mathrm{mL} \text {. }\end{array}$ & 15,9 & 16,3 & 10,1 & 13,0 & 9,4 & 16,8 & 13,5 & 10,9 \\
\hline $\begin{array}{l}3 \text { - Fração } \\
\text { Diclorometano } \\
\text { 1,35 mg/mb }\end{array}$ & 8,1 & 11.4 & 10,6 & 12,3 & 10,3 & 11,6 & 18,8 & 9,6 \\
\hline $\begin{array}{l}4 \text { - Fraçăo Acetato de } \\
\text { etila } 0,9 \mathrm{mg} / \mathrm{mL}\end{array}$ & 11,3 & 14,1 & 10,5 & 12,4 & 7,6 & 12,3 & 11,3 & 8,8 \\
\hline $\begin{array}{l}5 \text { - Fraçăo Metanólica } \\
7,5 \text { mg/mL }\end{array}$ & 11,3 & 13,4 & 10,0 & 10,8 & 11,1 & 13,4 & 13,1 & 8.6 \\
\hline $\begin{array}{l}6 \text { - Fração Etanólica } \\
9 \text { mgimo. }\end{array}$ & 16,3 & 16,7 & 10,4 & 10,3 & 8,0 & 16,1 & 15,6 & 10,4 \\
\hline $\begin{array}{l}7 \text { - Digluconato de } \\
\text { Clorexidina } 0,2 \% \\
\text { (controle positivo) }\end{array}$ & 19,6 & 20,6 & 17,1 & 20,0 & 16,0 & 24,8 & 18,1 & 20,5 \\
\hline $\begin{array}{l}\text { Controle dos } \\
\text { microrganismos }\end{array}$ & + & + & + & + & + & + & + & + \\
\hline Controle com etanol & 0 & 0 & 0 & 0 & 0 & 0 & 0 & 0 \\
\hline
\end{tabular}

NOTA: S.p.- Streptococcus pyogenes

S.mi- Streptococcus mitis

S.e.- Staphylococcus epidermidis

S.a - Staphylococcus aureus

P.a - Pseudomonas aeruginosa

S.m - Streptococcus mutans

P.d - Placa dental

C.a - Candida albicans

A Tabela 1 apresenta as médias, e aplicando-se o teste de Tukey nível de significância $=0,05$, podemos avaliar o comportamento dos microrganismos em relação as diferentes soluções do extrato de agrião, Nasturtium officinale, ou seja, ação antimicrobiana das diferentes soluções, frente a diferentes microrganismos:

Analisando-se os resultados da relação Streptococcus pyogenes em relação as diferentes soluções (Tabela 1), observou-se que a solução 1 apresentou diferença significativa em relação à solução 3 ; a solução 2 apresentou diferença significativa em relação às soluções $1,3,4$ e 5; a solução 3 não apresentou diferença significativa; a solução 4 apresentou diferença significativa em relação às soluções 1 e 3; a solução 5 apresentou diferença significativa em relação às soluções 1 e 3 ; a solução 6 : apresentou diferença significativa em relação às soluções $1,3,4$ e 5 ; e a solução 7 apresentou diferença significativa em relação às soluções 1, 2, 3, 4, 5 e 6 .

Com base nos resultados da relação Streptococcus mitis em relação as diferentes soluções (Tabela 1) temos que a solução 1 apresentou diferença significativa em relação às soluções 3,4 e 5 ; solução 2 apresentou diferenças significativas em relação às soluções 3,4 e 5 ; a solução 6 apresentou diferença significativa em relação às soluções 3 e 5 ; a solução 7 apresentou diferença significativa em relação às soluções $1,2,3,4,5$ e 6 . 
hoje, pode ser utilizada profilaticamente e como agente terapêutico em pessoas com cáries ativas (THYLSTRUP e FEJERKOV, 1995).

Nesta perspectiva é compreensível observarmos que a média dos halos de inibição não se comportaram de forma semelhante para todas as soluções (frações) e microrganismos. O estudo mostrou-nos que a fração diclorometano (solução 3) promoveu maior inibição no controle do crescimento de bactérias da placa dentária em torno de $18,8 \mathrm{~mm}$, enquanto que a solução $7(\mathrm{CH})$ foi de $18,1 \mathrm{~mm}$, estatisticamente sem diferenças significativas. Os efeitos das soluções mudaram de microrganismo para microrganismo, ou seja, o efeito da solução interagiu com o microrganismo.

\section{CONCLUSÃO}

$\mathrm{Na}$ avaliação "in vitro" da ação antimicrobiana, das diferentes frações obtidas do extrato de agrião Nasturtium officinale R. BR. frente aos microrganismos da cavidade bucal e placa dental conclui-se que:

- A solução 1 mostrou-se eficaz no controle do crescimento dos S. mitis e S. Mutans.

- A solução 2, apresentou eficácia no controle do crescimento dos S. mitis, S. mutanse S. pyogenes.

- A solução 3 foi mais eficaz na inibição da formação da placa dentária, superando a solução 7 .

- Asolução 4 inibiu o crescimento dos S. mitis.

- A solução 5 inibiu o crescimento dos S. mitis e S. mutans e da formação da placa dentária.

- A solução 6 mostrou-se eficaz para S. mitis, S. pyogenes, S. mutans e placa dentária.

\section{REFERÊNCIAS}

AXELSSON P.; LINDHE J. The effect of a preventive programme on dental plaque, gingivitis and caries in schoolchildren. Results after one and two years. $\mathbf{J}$ Clin Periodontol, v. 1, n. 2, p. 126-138, 1974.

AXELSSON P.; LINDHE J. The effect of controlled oral hygiene procedures on caries and periodontal disease in adults. J. Clin Periodontal, v. 5, n. 2, p. 133-151, 1978.

BLUMENTHAL, M.; GOLDBERG, A.; BRINCKMAANN, J; Herbal medicine, 1. ed., Integrative Medicine Communications, p. 404-407, 2000.

BUFFON, M. C. M.; LIMA, M. L. C.; GALARDA, I.; COGO, L. Avaliação da eficácia dos extratos de Malva sylvestris, Calêndula officinalis, Plantago major e Curcuma zedoarea no controle do crescimento das bactérias da placa dentária. Estudo "in vitro". Revista Visão Acadêmica, v. 2, n. 1, p. 31-37. Janeiro/Junho, 2001.

BUISCHI, Y. Salivary streptococcus mutans and caries prevalence in brazilian schoolchildren. Community Dent Oral Epidemiol, v. 17, n. 1, p. 28 30, 1989. 
BURNETT, G. W.; SCHERP, H. W.: SCHUSTER, G. S. Microbiologia Oral e Doenças Infecciosas. 4. ed. Guanabara, p. 205-215, 1985.

CARVALHO, J. L. S. Contribuição ao estudo fitoquímico e analítico no Nasturtium officinale R. Br., Brasicaceae. Curitiba, 88 f. Dissertação (Mestrado em Ciências Farmacêuticas) Setor de Ciências da Saúde, Universidade Federal do Paraná, 2001.

CURY, J. A. Controle Químico da Placa Dental. In: KRIGER, L. (Coord.). Promoção de saúde bucal: Paradigma, Ciência, Humanização. São Paulo: 3ed. Artes Médicas/ABOPREV, p. 141-151, 2003.

DE MICHELI, G.; SARIAN, R. Placa bacteriana - Controle Químico. Revista da Associação Paulista de Cirurgiões Dentistas, v. 44, n. 6, p. 330 333, novembro / dezembro, 1990.

DIXON, R. A.: DEY, P. M.: LAMB, C. J. Adv. Enzimol. 55, p. 1, 1983.

GETAHUN S. M.; CHUNG F. L. Conversion of glucosinolates to isothiocyanates in humans after ingestion of cooked watercress. Cancer Epidemiol Biomarkers Prev, v. 8, n. 5, p. 447-451, 1999.

GLICKMAN I. Periodontal diseases. Rev Odontol Ecuat, v. 19, n. 60, p. 1-8, 1974. GUYOT, M. A. M. Perspectivas da fitoterapia. Acta. Farm. Bonaerense, v. 9, n. 2, p. 131 - 138, 1990.

KORNMAN K. The microbiologic etiology of periodontal disease. Compend Contin Educ Dent. Suppl 7: S173-5, S178, 1986.

LOGGIA, R.D. Piante officinali per infuse e tisane. Organizzazione Editorale Medico Farmacêutica, 3 ed., p. 354, 1993.

MEDEIROS, U. V. Aspectos gerais no controle da placa bacteriana. Controle de placa bacteriana em saúde pública. Revista da Associação Paulista de Cirurgiões Dentistas, v. 45, n. 3, p. 479 483, 1991.

OSAWA, K. Studies of antibacterial activity of plant extracts and their constituents against periodontopathic bacteria. Bull Tokyo Dent Call, v. 31, n. 1, p. 17 21, 1990 a.

OSAWA, K. Inhibitory effects of aqueous extract of cacao bean husk on collagenase of Bacteroides gingivalis. Bull Tokyo Dent Coll. v. 31, n. 2, p. 125-128, $1990 \mathrm{~b}$.

SATO, M.; FUJIWARA, S.; TSUCHIYA, H.; FUGII, T.; LIMUNA, M.; TOSA, H.; OHKAWA, Y. J. Ethnopharmacol, 54, p. 171, 1996.

SOEJARTO, D. D. Biodiversity prospecting and benefit sharing: perspectives from the field. J. Ethnopharmacol., v. 51, p. 1-15, 1996.

SUOMI J. D. Prevention and control of periodontal disease. J Am Dent Assoc, v. 83, n. 6, p. 1271-1287, 1971.

THYLSTRUP, A., FEJERSKOV, O. Cariologia Clínica. 2. ed., São Paulo: Ed. Santos, 421 p., 1995.

WALL M. E.; WANI M. C. Camptothecin: discovery to clinic. Ann N Y Acad Sci, v. 803, p. 1-12, 1996. 